\title{
Aplikasi Metode Geolistrik Tahanan Jenis untuk Identifikasi Zona Bidang Gelincir Tanah Longsor Studi Kasus Desa Nglajo Kec. Cepu Kab. Blora
}

\author{
Eka Yuliana $^{1}$, FX. Yudi Tryono ${ }^{2}$, dan Eko Minarto ${ }^{1}$ \\ ${ }^{1}$ Departemen Fisika, Fakultas Matematika dan Ilmu Pengetahuan Alam, Institut Teknologi Sepuluh Nopember (ITS) \\ ${ }^{2}$ Pusat Pengembangan Sumber Daya Manusia Minyak dan Gas Bumi Cepu \\ e-mail: eko.minarto@googlemail.com
}

\begin{abstract}
Abstrak-Metode geofisika semakin banyak digunakan untuk investigasi tanah longsor. Longsor secara periodik dipicu oleh curah hujan kritis, dan distribusi kadar air bawah permukaan merupakan faktor kunci yang mempengaruhi stabilitas lapisan tanah. Begitu pula yang ditemui disekitar Jalan Taman Bahagia sebelah selatan Taman Makam Pahlawan Nglajo Kecamatan Cepu terjadi gerakan permukaan tanah yang menyebabkan jalan utama komplek perumahan Nglajo rusak walaupun sudah beberapa kali diperbaiki. Analisa data lapangan diperoleh berdasarkan survei geolistrik tahanan jenis dengan metode konfigurasi Wenner dan Dipole-dipole. Zona bidang gelincir dapat terlihat pada penampang resistivitas 2D yang teletak di lintasan 2, 3 dan 4. Dimana bidang gelincir pada daerah penelitian merupakan bidang batas antara batuan dengan nilai resistivity kurang dari $2,4 \Omega \mathrm{m}$ diinterpretasikan sebagai batuan aluvium berupa batuan lempung dari Formasi Lidah tersebar dan membentang dari arah utara ke selatan. dengan kedalaman yang berbeda-beda dari 0,5 hingga 11 meter dibawah permukaan tanah.
\end{abstract}

Kata Kunci-Resistivitas, Tanah Longsor, dan Zona Bidang Gelincir.

\section{PENDAHULUAN}

$\mathrm{B}$ ENCANA tanah longsor telah menyebabkan kerusakan infrastruktur yang luas dan mengancam kehidupan manusia selama berabad-abad. Longsor ini secara periodik dipicu oleh curah hujan kritis dan distribusi kadar air bawah permukaan, yaitu faktor kunci yang mempengaruhi stabilitas lapisan tanah. Selain itu, ada potensi kejadian bencana tanah longsor dapat meningkat di masa depan karena perubahan iklim.

Penampang struktur bawah permukaan yang diperoleh dari pengolahan data survei geolistrik resistivitas menunjukkan, bidang gelincir terlihat dari contrast resistivity antar dua batuan yang saling berdekatan [1]. Setiap material pada umumnya memiliki sebuah sifat menghambat aliran listrik yang melalui material tersebut. George Simon Ohm menyatakan bahwa harga resistivitas untuk suatu medium menghantar dengan panjang $l$ dan luas penampang $A$, yang diberi potensial $V$ adalah sebagai berikut:

$$
R=\rho \frac{l}{A}
$$

Resistivitas suatu medium adalah tahanan atau hambatan yang diberikan oleh medium tersebut terhadap arus listrik yang melaluinya [2]. Dalam hal ini persamaan (1.1) disebut juga dengan nilai resistivitas sebenarnya (true resistivity). Dimana $\mathrm{R}$ adalah nilai resistansi atau faktor tetap yang disebut dengan hambatan atau tahanan listrik dalam satuan

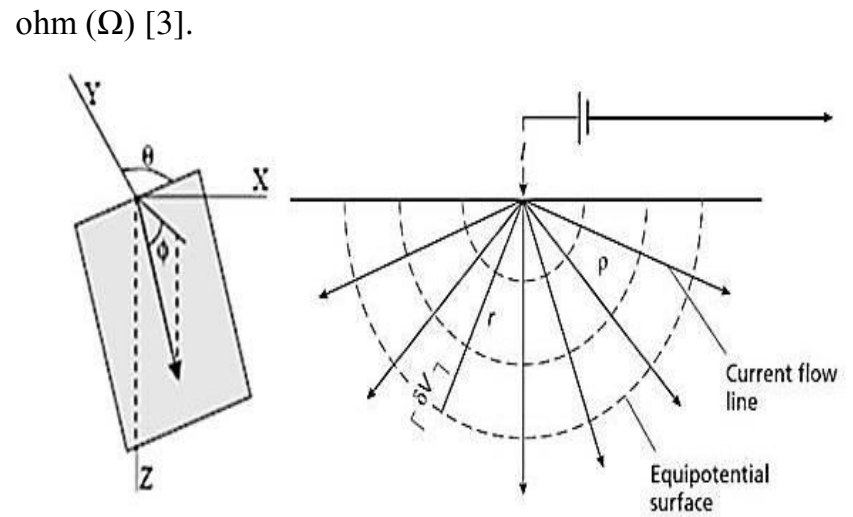

Gambar 1. Arus Tunggal di Permukaan Medium Homogen Isotropis (Kearey, 2002).

Model bumi yang berbentuk setengah bola homogen isotropis memiliki konduktivitas udara sama dengan nol. Dengan demikian, arus $I$ yang dialirkan akan tersebar ke semua arah dengan besar yang sama. Dikarenakan arus yang mengalir simetri terhadap arah $\theta$ dan $\phi$ pada arus tunggal, dengan demikian potensial tiap titik yang berhubungan dengan sumber arus pada permukaan bumi yang homogen isotropis adalah [4]:

$$
V=\frac{1}{r} \frac{I \rho}{2 \pi} \text { atau } \rho=2 \pi r \frac{\Delta V}{I}
$$

Untuk kasus tidak homogen, bumi diasumsikan berlapislapis dengan masing-masing lapisan mempunyai harga resistivitas yang berbeda. Tahanan jenis semu (apparent electrical resistivity) atau $\rho_{a}$ yang didapatkan dari persamaan berikut:

$$
\rho_{a}=\frac{R A}{l}
$$

Resistivitas semu merupakan resistivitas dari suatu medium fiktif homogen yang ekuivalen dengan medium berlapis yang ditinjau [3].

Tabel 1.

Resistivitas batuan sediment (Telford et al. 1976: 455)

\begin{tabular}{cc}
\hline \hline Resistivitas batuan sediment (Telford et al. 1976: 455) \\
\hline Batuan & Resistivitas $(\Omega \mathrm{m})$ \\
\hline Serpihan gabungan & $20-2 \times 10^{3}$ \\
Argillites & $10-8 \times 10^{2}$ \\
Konglometar & $2 \times 10-10^{4}$ \\
Batu pasir & $1-6,4 \times 10^{8}$ \\
Batu Gamping & $50-10^{7}$ \\
Dolomite & $3,5 \times 10^{2}-5 \times 10^{3}$ \\
Lempung basah tidak gabungan & 20 \\
Marls & $3-70$ \\
Lempung basah tidak gabungan & $1-100$ \\
Alluvium dan pasir & $10-800$
\end{tabular}




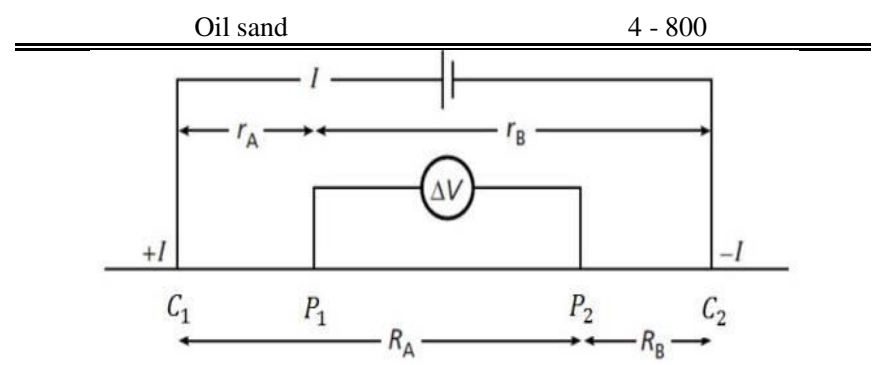

Gambar 2. Susunan elektroda pada survei geolistrik tahanan jenis [3].

Geolistrik merupakan metode geofisika yang mempelajari sifat listrik di dalam bumi dan bagaimana cara mendeteksinya dipermukaan bumi. Pada metode geolistrik tahanan jenis, arus listrik diinjeksikan kedalam bumi melalui dua elektroda arus (C). Kemudian beda potensial diukur melalui dua elektroda potensial $(\mathrm{P})$. Tegangan listrik yang timbul akibat aliran arus listrik dalam tanah akan diukur menggunakan multimeter yang dihubungkan dengan dua elektroda P [5].

Dari hasil pengukuran arus dan beda potensial untuk setiap jarak elektroda yang berbeda kemudian dapat diturunkan variasi harga hambatan jenis masing-masing lapisan dibawah titik ukur (sounding point).

$$
\begin{aligned}
& \Delta V=V_{P 1}-V_{P 2} \\
& \Delta V=\frac{\rho I}{2 \pi}\left(\frac{1}{r_{A}}-\frac{1}{r_{B}}-\frac{1}{R_{A}}+\frac{1}{R_{B}}\right)
\end{aligned}
$$

Faktor geometri adalah besaran koreksi terhadap perbedaan letak titik pengamatan, dimana dapat dihitung dengan [6]:

$$
\begin{aligned}
& \rho_{a}=K\left(\frac{\Delta V}{I}\right) \\
& K=\frac{2 \pi}{\left(\frac{1}{r_{1}}-\frac{1}{r_{2}}-\frac{1}{r_{3}}+\frac{1}{r_{4}}\right)}
\end{aligned}
$$

Dalam survei data geolistrik dikenal adanya Constant Separation travering (CST) atau yang juga diketahui sebagai "electrical profiling". CST adalah metode yang digunakan untuk menentukan variasi lateral dari sebuah pengolahan data resistivitas [3]. Selain itu, metode ini mampu menentukan perbedaan yang signifikan di dalam parameter geolistrik dari top soil (tanah penutup) dengan material lain, daerah yang retak atau patahan, dan batuan bawah tanah [7].

Konfigurasi Wenner merupakan konfigurasi yang membutuhkan tempat yang sangat luas dan dapat digunakan untuk metode mapping. Elektroda potensial ditempatkan pada bagian dalam dan elektroda arus pada bagian luar dengan jarak antar elektroda sebesar a. Dalam survei dengan konfigurasi Wenner, keempat elektroda perlu dipindahkan secara berturut-turut. Persamaan faktor geometri $(K)$ dan resistivitas semu $\left(\rho_{a}\right)$ untuk konfigurasi Wenner yaitu [6]:

$$
\begin{aligned}
& K=\frac{2 \pi}{\left[\left(\frac{1}{a}-\frac{1}{2 a}\right)-\left(\frac{1}{2 a}+\frac{1}{a}\right)\right]} \\
& \rho_{a}=2 \pi a \frac{\Delta V}{I}
\end{aligned}
$$

Konfigurasi Dipole-dipole merupakan gabungan dari teknik profiling dan depth sounding, sehingga jenis konfigurasi ini merupakan salah satu konfigurasi yang umumnya digunakan dalam eksplorasi geofisika. Konfigurasi Dipole-dipole menempatkan jarak elektroda arus. Persamaan faktor geometri $(K)$ dan resistivitas semu $\left(\rho_{a}\right)$ untuk konfigurasi Dipole - dipole yaitu: [6]

$$
\begin{aligned}
K & =\pi n(n+1)(n+2) a \\
\rho_{a} & =\pi n(n+1)(n+2) a\left(\frac{\Delta V}{I}\right)
\end{aligned}
$$

Bumi terdiri dari beberapa lapisan batuan dengan jenis yang berbeda, maka masing-masing lapisan mempunyai harga resistivitas tertentu [8]. Proses inversi bertujuan untuk mencari model yang diberikan oleh respon yang mendekati atau mirip nilai pengukuran lapangan. Proses yang dilakukan untuk memperoleh data prediksi hasil pengukuran berdasarkan parameter fisis yang sudah diketahui, maka dilakukan forward atau forward modelling [9].

Zona labil merupakan suatu wilayah yang menunjukkan daerah itu mempunyai kondisi tanah yang terus bergeser. Geseran tanah yang sering terjadi adalah tanah longsor yang merupakan proses perpindahan massa tanah secara alami dari tempat yang tinggi ke tempat yang lebih rendah [4]. Salah satu komponen yang sangat berpengaruh pada terjadinya tanah longsor adalah bidang gelincir (slip surface). Tanah yang akan bergerak bila terjadi kelongsoran adalah bagian tanah yang berada di atas bidang gelincir tersebut. Bidang gelincir berada diantara bidang yang stabil (bedrock) dan bidang yang bergerak atau bidang yang tergelincir. Bedrock sendiri merupakan batuan dasar kokoh (consolidated), terendap dan terkubur dibawah tanah atau berada dibawah lapisan tanah yang lain yang tidak kokoh (unconsolidated) [10].

Penelitian ini dilakukan untuk mengetahui susunan lapisan bawah permukaan tanah, sehingga dapat diketahui penggambaran pergerakan massa tanah, tingkat lateral longsoran serta adanya zona bidang gelincir yang memiliki kedalaman serta arah tertentu yang ada pada daerah longsoran.

\section{URAIAN PENELITIAN}

Pengukuran data resisitivitas 2D di Desa Nglajo Kecamatan Cepu Kabupaten Blora Jawa Tengah, yang berlokasi di sekitar Jalan Taman Bahagia sebelah selatan Taman Makam Pahlawan Nglajo. Kecamatan Cepu berjarak kurang lebih $38 \mathrm{~km}$ dari kota Kabupaten Blora. Kabupaten Blora sendiri tersusun dari morfologi dataran rendah dan perbukitan dengan ketinggian 20 hingga 280 mdpl. Berdasarkan hasil pengamatan geologi, di daerah Cepu tersusun oleh litologi berupa batu lempung yang sangat tebal dengan sifat plastis berwarna kehijauan dengan selingan berupa batu gamping yang kaya akan foraminifera plankton. Berdasarkan ciri fisik litologinya dapat disimpulkan bahwa lokasi telitian terletak pada Formasi Lidah. Umur formasi ini dari Pliosen Atas-Pleistosen [11].

Pekerjaan pra survei terlebih dahulu dilakukan penentuan lokasi titik pengukuran dan mencatat posisi dan ketinggian setiap titik pengukuran. Kemudian dilakukan proses pengambilan data di lapangan. Data yang diperoleh dari survei geolistrik tahanan jenis adalah nilai resistivitas semu (apparent resistivity). Data tersebut harus diolah hingga didapatkan nilai resistivitas yang sebenarnya (true resistivity).

Interpretasi data yang dilakukan dengan melihat karakteristik atau kecenderungan harga resistivitas yang diperoleh dari hasil pemodelan dengan Software Res2Dinv dan AGI EarthImager. Cara menginterpretasi adalah dengan mengkorelasikan penampang 2D hasil pengolahan data software Res2Dinv dan AGI EarthImager 2D yang berupa 
informasi nilai resistivitas, kedalaman, dan ketebalan material dengan informasi geologi maupun penelitian terdahulu. Berikut adalah gambaran dari alur proses penelitian yang dilakukan:

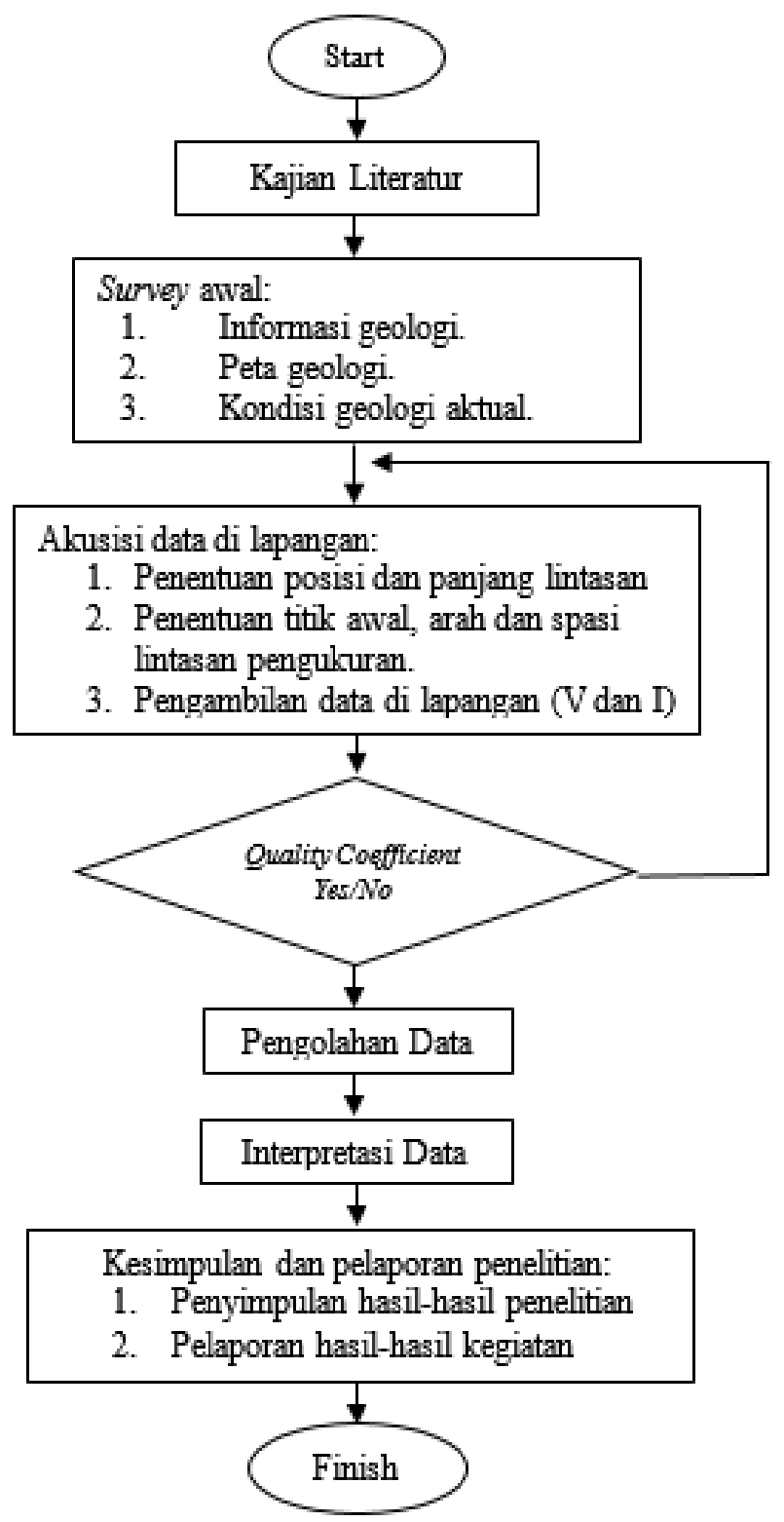

\section{ANALISA DATA DAN PEMBAHASAN}

Pengambilan data pada area telitian dilakukan dengan konfigurasi Wenner dan konfigurasi Dipole-dipole pada 6 lintasan dengan panjang masing-masing lintasan 110 meter. Dimana terdapat 4 lintasan dengan posisi saling sejajar satu sama lainnya yang melintang dari arah selatan ke utara. Keempat lintasan tersebut yaitu lintasan 1, 2, 3 dan 4 diukur dengan menggunakan konfigurasi Wenner. Sedangkan 2 lintasan lainnya, yaitu lintasan 5 dan 6 dengan posisi yang juga saling tegak lurus melintang dari arah timur ke barat diukur dengan konfigurasi Dipole-dipole.

Dapat dilihat pada Gambar 3.1 dan Gambar 3.2 yang menampilkan penampang 2D hasil pengolahan data resistivitas dari lintasan 3, posisi lintasan 3 berada ditengahtengah area telitian, sehingga lintasan 3 dapat menjadi representasi dari kelima lintasan yang lain. Lintasan 3 sepanjang 110 meter melintang dari arah selatan ke utara, dengan arah lintasan N355E. Titik 0 pengukuran terletak pada koordinat E564751,55 dan N9209817,84 dengan elevasi 63,58 mdpl, sedangkan pada titik 110 meter terletak pada koordinat E564740,39 dan N9209916,46 dengan elevasi 63,84 mdpl.

Jika penampang lintasan 3 hasil olahan perangkat lunak Res2DInv diinterpretasi terdapat gradasi warna dari hijau tua hingga biru tua dengan nilai resistivitas kurang dari 2,46 $\Omega \mathrm{m}$. Gradasi warna tersebut diperkirakan mewakili nilai resistivitas batuan aluvium seperti batuan lempung dan pasir yang terdapat pada area telitian. Lapisan tersebut terletak pada kedalaman di bawah 2,7meter yang terletak di dekat titik 0 pengukuran hingga kedalaman di bawah 7 meter pada elektroda 90 meter dekat titik akhir pengukuran.

Penampang lintasan 3 hasil olahan perangkat lunak AGI EarthImager 2D terdapat gradasi warna dari biru muda hingga biru tua dengan nilai resistivitas kurang dari $2,4 \Omega \mathrm{m}$. Seperti halnya pada interpretasi menggunakan Res2DInv, gradasi warna tersebut diperkirakan mewakili nilai resistivitas batuan aluvium seperti batuan lempung dan pasir yang terdapat pada area telitian. Lapisan tersebut menyebar sepanjang lintasan 3 dengan kedalaman 3 meter dari permukaan atau pada elevasi 62,8meter yang terletak di dekat titik 0 pengukuran hingga kedalaman di bawah 7,5 meter pada elektroda 94 meter dekat titik akhir pengukuran.

Gambar 3. Diagram alur penelitian.

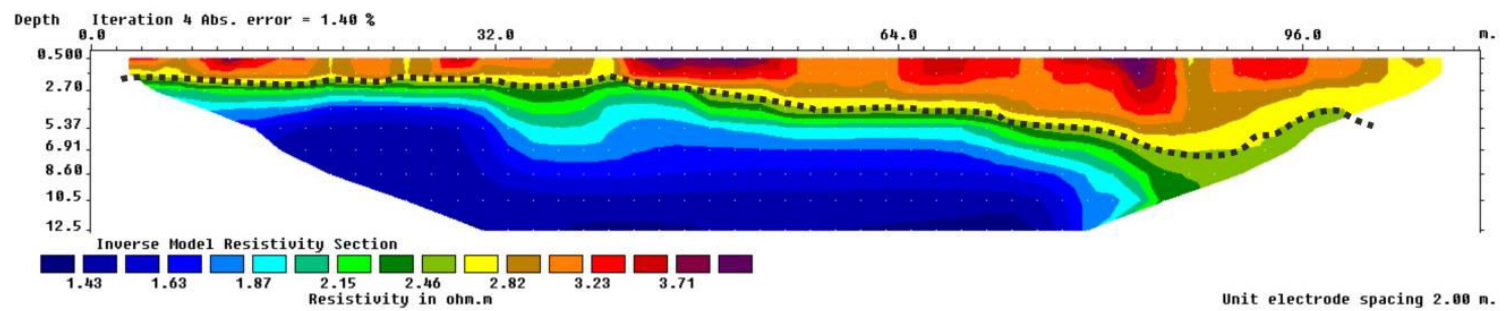

Gambar 4. Penampang hasil pengolahan data resistivitas dengan perangkat lunak Res2DInv pada Lintasan 3. 


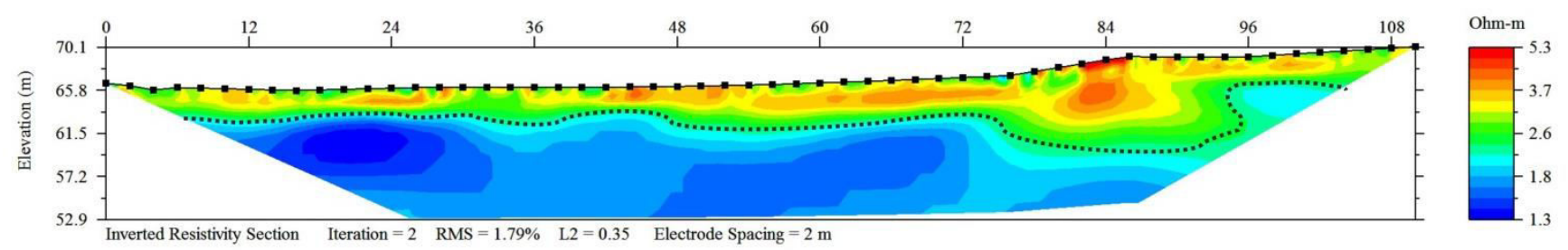

Gambar 5. Penampang hasil pengolahan data resistivitas dengan perangkat lunak AGI EarthImager 2D pada Lintasan 3.

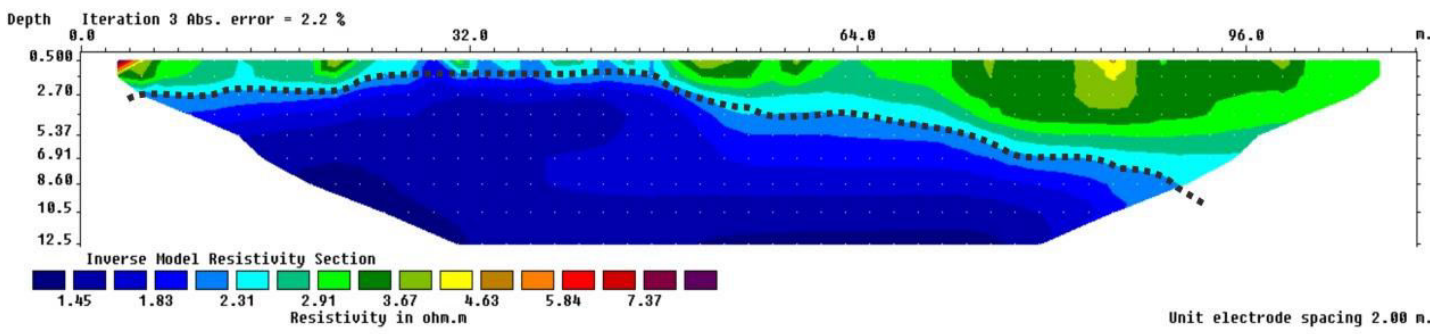

Gambar 6. Penampang hasil pengolahan data resistivitas dengan perangkat lunak Res2DInv pada Lintasan 2.

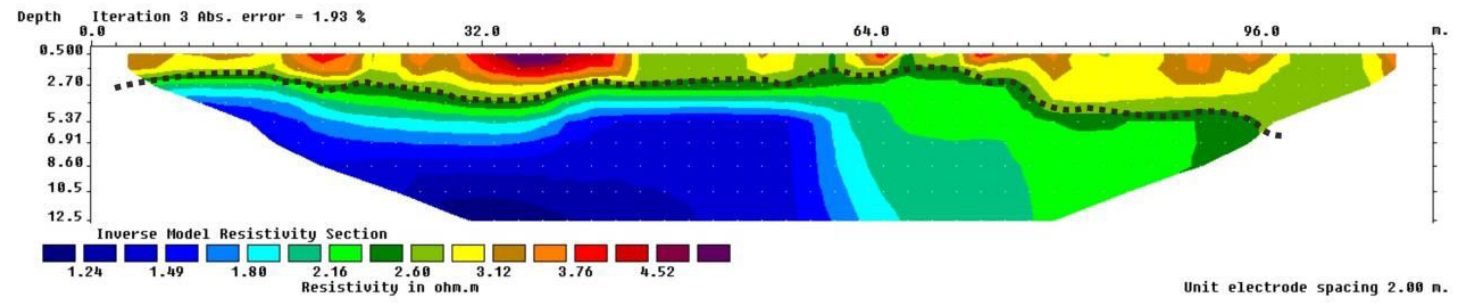

Gambar 7. Penampang hasil pengolahan data resistivitas dengan perangkat lunak Res2DInv pada Lintasan 4.

Selanjutnya ditinjau dari lintasan ukur yang lain, yaitu lintasan 1, 2, 4, 5 dan 6 hasil pengolahan data resistivitas 2D menggunakan perangkat lunak lunak AGI EarthImager 2D didapatkan penampang yang kurang lebih sama dengan yang diolah dengan perangkat linak Res2DInv. Garis putus-putus berwarna hitam pada penampang menunjukkan letak bidang gelincir dibawah permukaan tanah. Dimana hasil tersebut menunjukkan struktur tanah dan batuan dengan nilai resistivitas kurang dari 2,4 $\Omega \mathrm{m}$ diidentifikasikan sebagai anomali bidang gelincir yang tersusun dari batuan aluvium berupa lempung dan pasir.

Anomali dari keenam penempang lintasan yang diolah dengan perangkat lunak Res2DInv diperkirakan adalah batuan aluvium adalah lapisan batu lempung dan pasir. Batu lempung ini memiliki nilai resistivitas yang rendah karena sifat ukuran butir yang halus dan kecil serta faktor adanya sedikit kandungan air dalam batu lempung ini menyebabkan nilai resistivitasnya semakin rendah dibandingkan batuan disekelilingnya. Sedangkan batu pasir yang memiliki nilai resistivitas yang sedang ini diduga merupakan sisipan batu pasir yang cukup jenuh air sehingga dapat menurunkan nilai resisitivitasnya. Sedangkan gradasi warna kuning hingga merah yang memiliki nilai resistivitas tinggi kemungkinan adalah lapisan batuan lapuk dan tanah penutup atau endapan dimana rongga-rongga yang dapat terisi oleh air yang berasal dari air permukaan. Anomali berupa bidang gelincir tanah longsor terlihat pada lintasan 2, 3 dan 4 dimana bidang gelincir tersebar dan membentang dari arah utara ke selatan.

Hasil investigasi lebih lanjut dengan teknik sounding konfigurasi Wenner dilakukan dengan tinjauan pada lintasan 3. Pengolahan data sounding dilakukan dengan perangkat lunah IP2Win menunjukkan struktur tanah dan batuan sebanyak tiga jenis batuan. Pada Gambar 3.3 menampikan susunan lapisan tanah dan batuan dengan ketebalan dan variasi kedalaman masing-masing. Titik sounding terletak di Lintasan 3 dimana proses pengambilan data di lapangan menggunakan konfigurasi Wenner memiliki jangkauan kedalaman hingga 15,5 meter dari muka tanah. Terdapat empat lapisan tanah yang terlihat menyusun lapisa bawah permukaan bumi sebagaimana yang tercantumkan pada Tabel 3.1. Jenis lapisan tanah berupa lempung basah diduga sebagai anomali bawah permukaan yang dicari yaitu sebuah bidang gelincir. Interpretasi data dengan metode sounding kali ini dilakukan dengan tujuan untuk mengetahui lebih detail susunan lapisan tanah dan batuan dengan ketebalan dan variasi letaknya pada kedalaman tertentu.

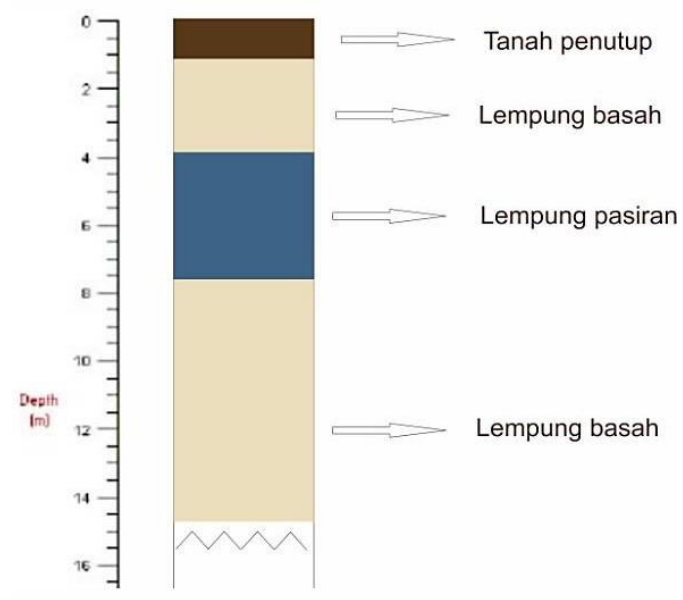

Gambar 8. Interpretasi bawah permukaan titik sounding pada lintasan 3.

Tabel 2.

Hasil interpretasi lapisan tanah pada titik sounding lintasan 3 


\begin{tabular}{ccc} 
Litologi & Resistivitas $(\Omega \mathrm{m})$ & Kedalaman $(\mathrm{m})$ \\
\hline Tanah penutup & $3.01-2.41$ & $0-1.06$ \\
Lempung basah & $2.41-6.03$ & $1.06-3.92$ \\
Pasir lempungan & $6.03-0.218$ & $3.92-7.26$ \\
Lempung basah & $0.218-2.14$ & $>7.26$ \\
\hline \hline
\end{tabular}

Terdapat kesesuaian antara hasil interpretasi data sounding dengan informasi peta geologi di daerah Cepu dan sekitarnya. Batuan dasar yang memiliki nilai resistivitas dibawah 2,4 $\Omega \mathrm{m}$ yang diinterpretasikan sebagai batuan aluvium berupa batuan lempung dari Formasi Lidah. Formasi Lidah tertutup oleh endapan alluvial dan endapan sungai. Formasi Lidah tertutup oleh batuan aluvium yang tersusun dari lempung, pasir, kerikil dan kerakal. Memperkuat asumsi bahwa di wilayah Cepu yang merupakan bagian dari Formasi Lidah mempunyai kondisi bawah permukaan yang terdiri batuan aluivium salah satuya adalah lempung dimana pada kasus ini dianggap sebagai anomali dari zona bidang gelincir tanah longsor. Dari peta geologi terlihat keberadaan struktur geologi yang relatif komplek, hal ini menunjukkan bahwa daerah tersebut sudah mengalami proses geologi yang sangat kuat.
Dilakukan pengolahan dengan perangkat lunak Res2DInv dan AGI EarthImager 2D pada data sekunder hasil pengukuran data resistivitas dari keenam lintasan. Kemudian dilakukan interpretasi dan korelasi antara penampang hasil pemodelan dari kedua perangkat lunak yang digunakan. Tujuan dilakukannya korelasi hasil pemodelan penampang resistivitas 2D adalah untuk mempermudah analisa struktur bawah permukaan. Selain itu korelasi kedua hasil penampang tersebut dapat menghindari ambiguitas atau multitafsir mengingat tidak tersedianya satupun data bor (bore hole) hasil pengukuran data lapangan. Sehingga analisis yang dilakukan menggunakan metode deskriptif ini nantinya akan dapat menggambarkan struktur bawah permukaan dengan akurat.

Berangkat dari itu, untuk mendapatkan gambaran yang jelas tentang bidang gelincir di masing-masing lintasan, maka penulis menginterpretasikan hasil pengolahan data geolistrik dengan menggunakan software AGI EarthImager $2 \mathrm{D}$ dengan membagi level warna penampang hanya menjadi 2 warna saja. Dengan tujuan untuk mempermudah identifikasi lapisan yang manakah yang merupakan zona bidang gelincir tanah longsor.

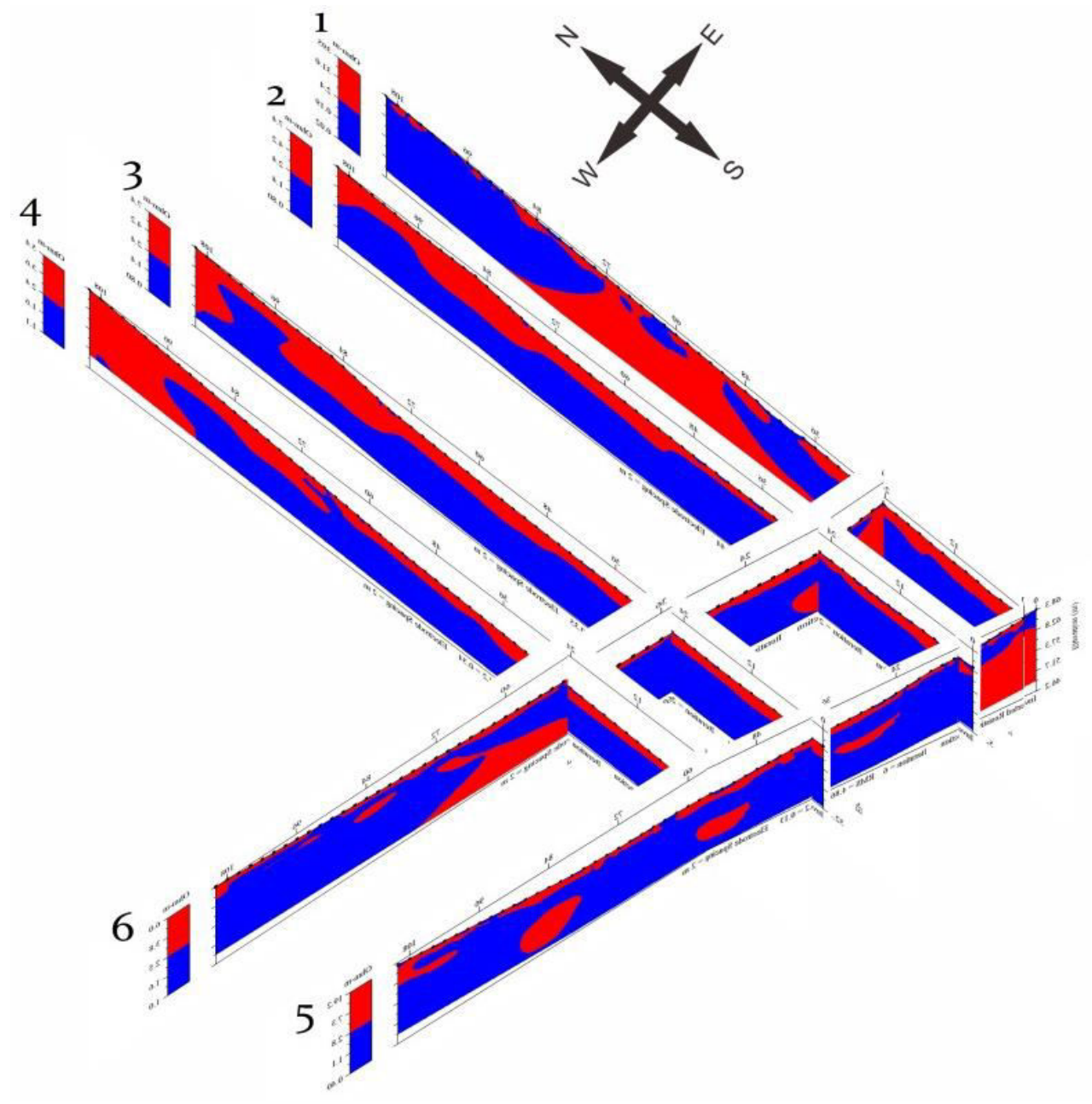

Gambar 9. Korelasi keenam penampang resistivitas 2D.

Pada Gambar 3.6 diatas, keenam penampang resistivitas 2D hasil pengolahan data dengan perangkat lunak AGI EarthImager 2D dikorelasikan sesuai dengan posisi lintasan dan topografinya. Hasil korelasi tersebut dapat menginterpretasikan dengan jelas dugaan adanya zona bidang gelincir tanah longsor pada area telitian. Pembagian ini berdasarkan identifikasi anomali permukaan yaitu untuk nilai resistivitas kurang dari 2,4 $\Omega \mathrm{m}$ sebagai batuan dasar yang diwaili dengan warna biru pada penampang. Selanjutnya nilai resistivitas diatas $2,4 \Omega \mathrm{m}$ sebagai wet clay atau tanah urug/rombakan diwakili dengan warna merah. 
Seperti yang ditunjukkan pada lapisan warna merah pada penampang Gambar 3.6. Hasil interpretasi penampang bawah permukaan 2D dari semua lintasan, dapat diambil asumsi bahwa pada daerah penelitian memiliki nilai resistivitas diatas 2,4 $\Omega \mathrm{m}$ dapat diinterpretasikan sebagai batuan lepas (rombakan dari urugan) atau batuan lempung mengandung air (wet clay) sehingga dapat diinterpretasikan bahwa bidang gelincir pada gerakan tanah di daerah telitian merupakan bidang batas antara batuan dengan nilai resistivitas kurang dari $2,4 \Omega \mathrm{m}$

Sedangkan lapisan warna biru pada penampang dari Gambar 3.6 diperkirakan pula sebagai zona jenuh air tanah yang mendominasi lapisan bawah permukaan. Salah satu ciri zona jenuh air adalah bersifat kedap air yang tidak mampu mengalirkan air ataupun tertembus oleh air. Curah hujan yang tinggi mengakibatkan air yang meresap ke dalam tanah akan menambah bobot tanah. Jika air tersebut menembus sampai tanah kedap air yang berperan sebagai bidang gelincir, maka tanah menjadi licin dan tanah pelapukan di atasnya akan bergerak mengikuti lereng dan keluar lereng.

Bidang gelincir dapat diperoleh dari contrast resistivity antar dua batuan yang saling berdekatan. Bila resistivitas lapisan atasnya lebih tinggi dari resistivitas lapisan bawahnya, maka sangat memungkinkan terjadi longsoran hal ini dikarenakan lapisan tersebut akan mudah terkikis dan mengalir. Korelasi keenam penampang mennunjukkan bahwa pada setiap lintasan terdapat zona bidang gelincir dengan kedalaman yang berbeda-beda dari 0,5 hingga 11 meter dibawah permukaan tanah.

Topografi daerah telitian diketahui bahwa posisi area telitian lebih landai ke arah barat dan selatan. Zona bidang gelincir terdapat pad asemua lintasan. Yang sangat terlihat adalah pada lintasan 2, 3 dan 4 dimana bidang gelincir tersebar dan membentang dari arah utara ke selatan. Jenis pergerakan tanah longsor yang mungkin terjadi pada daerah ini adalah jenis rayapan (creeping). Jenis pergerakan ini dapat diidentifikasi dari jenis material penyusun struktur bawah permukaan daerah telitian. Daerah telitian memiliki batuan dasar berupa lempung dan diatas batuan dasar merupakan batuan rombakan yang berupa tanah lepas/ rombakan dari lempung.

\section{IV.KESIMPULAN}

Dari penelitian yang telah dilakukan dengan judul "Aplikasi Metode Geolistrik Tahanan Jenis untuk Identifikasi Zona Bidang Gelincir Tanah Longsor Studi Kasus Desa
Nglajo Kec. Cepu Kab. Blora" dapat ditarik kesimpulan sebagai berikut:

1. Data lapangan dimana nilai resistivitas yang diperoleh berdasarkan survei geolistrik tahanan jenis dapat digunakan untuk menentukan zona bidang gelincir.

2. Zona bidang gelincir dapat terlihat pada penampang resistivitas 2D yang teletak di lintasan 2, 3 dan 4. Dimana bidang gelincir tersebar dan membentang dari arah utara ke selatan. dengan kedalaman yang berbeda-beda dari 0,5 hingga 11 meter dibawah permukaan tanah.

3. Bidang gelincir pada daerah penelitian merupakan bidang batas antara batuan dengan nilai resistivitas kurang dari 2,4 $\Omega \mathrm{m}$ diinterpretasikan sebagai batuan aluvium berupa batuan lempung dari Formasi Lidah. Pergerakan tanah yang mungkin terjadi pada daerah ini adalah jenis rayapan (creeping). Daerah telitian memiliki batuan dasar berupa lempung dan diatas batuan dasar merupakan batuan rombakan lempung yang berupa tanah lepas.

\section{DAFTAR PUSTAKA}

[1] Z. I. Sugito and P.J. Indra, "Investigasi Bidang Gelincir Tanah Longsor Menggunakan Metode Geolistrik Tahanan Jenis di Desa Kebarongan Kec. Kemranjen Kab. Banyumas,” Berk. Fis., vol. 13, no. 2, pp. 49-54, 2010.

[2] A. Sadiku, Fundamentals of Electric Circuits, 5th ed. New York: Mc Graw Hill Inc, 2012.

[3] P. Kearey, M. Brooks, and I. Hill, An Introduction to Geophysical Exploration, 3rd ed. Blackwell Science L.td, 2002.

[4] J. M. Reynolds, An introduction to applied and environmental geophysics-Second Edition. United Kingdom: John Wiley \& Sons Ltd, 2011.

[5] Hendrajaya, Lilik, Arif, and Idam, "Monograf, Geolistrik Tahanan Jenis," Bandung, 1990.

[6] H. M. Loke, "Tutorial: 2-D and 3-D electrical imaging surveys," 2004. [Online]. Available: www.geoelectrical.com.

[7] S. Birlina, Darsono, and B. Legowo, "Interpretasi Data Geolistrik untuk Memetakan Potensi Air Tanah dalam Menunjang Pengembangan Data Hidrogeologi di Kabupaten Jombang, Jawa Timur," J. Fis. dan Apl., vol. 9, no. 2, 2013.

[8] W. . Prameswari, "Analisa Resistivitas Batuan dengan Menggunakan Parameter Dar Zarrouk dan Konsep Anisotropi," $J$. Tek. POMITS, vol. 1, no. 1, pp. 1-6, 2012.

[9] W. Menke, "Geophysical Data Analysis: Discrete Inverse Theory," Oregon, 1984.

[10] S. Yilmaz, "A Case Study of the Application of Electrical Resistivity Imaging for Investigation of a Landslide Along Highway," Int. J. Phys. Sci., vol. 6, no. 24, pp. 5843-5849, 2011.

[11] P. H, S. Djuehana, and R. Kapid, Strartigrafi dan Paleogeorafi Kenozoikum Pulau Jawa. Bandung: Institut Teknologi Bandung, 1985 . 